\title{
Methylphenidate Poisoning: Carpopedal Spasm in a Child
}

\author{
Mervan Bekdas ${ }^{\mathrm{a}, \mathrm{b}}$, Sevil Bilir Goksugur ${ }^{\mathrm{a}}$, Aynur Balaban, \\ Fatih Demircioglu
}

\begin{abstract}
Stimulant drugs including methylphenidate (MPH) are the firstline treatment for school-aged children and adolescents with attention-deficit hyperactivity disorder (ADHD). Since its availability, MPH overdoses have been seen more commonly similar to overdoses with other amphetamine-like drugs. Although the clinical manifestations include symphathomimetic findings like irritability, agitation, palpitation, hyperreflexia, seizures, hypertension, hyperventilation and hyperthermia, it may also cause stroke, tics, toxic psychosis, Tourette's syndrome and neuromuscular findings such as dyskinesia and paresthesia. Carpopedal spasm is a rare feature of MPH overdose. It may be triggered by alkalosis-induced hypocalcamia or cerebral vasoconstriction associated with hypocapnia. In this case report, we presented a 10-year-old girl who had carpopedal spasm after 3 - $4 \mathrm{~h}$ from taking the MPH with high dosage. Paper bag ventilation as the treatment had a significant improving effect on carpopedal spasm.
\end{abstract}

Keywords: Methylphenidate poisoning; Child; Carpopedal spasm

\section{Introduction}

Stimulant drugs including methylphenidate (MPH) are the first-line treatment for school-aged children and adolescents with attention-deficit hyperactivity disorder (ADHD). To achieve euphoria, stay awoke and improve alertness, higher doses may be taken as misuse of the drug. The abuse of MPH among teenagers has become more common and increased death rates have been reported. Since its availability, MPH

Manuscript accepted for publication December 9, 2013

${ }^{\mathrm{a} D e p a r t m e n t ~ o f ~ P e d i a t r i c s, ~ A b a n t ~ I z z e t ~ B a y s a l ~ U n i v e r s i t y, ~ M e d i c a l ~}$ Faculty, Bolu, Turkey

${ }^{\mathrm{b}}$ Corresponding author: Mervan Bekdas, Department of Pediatrics, Abant Izzet Baysal University, Faculty of Medicine, 14280 Golkoy, Bolu, Turkey. Email: merbek14@yahoo.com

doi: http://dx.doi.org/10.4021/jmc1616w overdoses have been seen more commonly similar to overdoses with other amphetamine-like drugs [1]. Widespread use of MPH raised serious concerns regarding abuse, toxic and possible life-threatening effects in pediatric patients. In 2004, 8,336 cases of MPH intoxication have been reported in the United States [2]. Clinical manifestations of MPH intoxication especially include central nervous system and cardiovascular system findings. Although the clinical manifestations include symphathomimetic findings like irritability, agitation, palpitation, hyperreflexia, seizures, hypertension, hyperventilation and hyperthermia, it may also cause stroke, tics, toxic psychosis, Tourette's syndrome and neuromuscular findings such as dyskinesia and paresthesia [1]. However, hyperventilation due to MPH overdose is rare and carpopedal spasm associated with overdose of MPH has not been reported to date.

\section{Case Report}

A 10-year-old girl applied to our emergency department with agitation, crying and wandering complaints. She had received a high dose of MPH (11 MPH 10-mg tablets) two times higher than the daily maximum allowed dose $2 \mathrm{~h}$ before the admission (3.14 mg/kg). Her blood pressure was 126/83 $\mathrm{mmHg}$, pulse rate was $114 / \mathrm{min}$, respiration rate was $22 / \mathrm{min}$ and temperature was $37.1{ }^{\circ} \mathrm{C}$. Her physical examination revealed tachypnea, palpitation, numbness in the hands and feet and carpopedal spasm. The initial blood tests revealed a creatinine level of $0.5 \mathrm{mg} / \mathrm{dL}$, blood urea nitrogen $17 \mathrm{mg} /$ $\mathrm{dL}$, albumin $4.2 \mathrm{~g} / \mathrm{dL}$, sodium $137 \mathrm{mmol} / \mathrm{L}$, potassium 3.7 $\mathrm{mmol} / \mathrm{L}$, chloride $96 \mathrm{mmol} / \mathrm{L}$, ionized calcium $1.08 \mathrm{mmol} / \mathrm{L}$ (N: 1.12-1.32), total calcium $9.1 \mathrm{mg} / \mathrm{dl}(\mathrm{N}: 8.1-10.4)$, magnesium $2.1 \mathrm{mg} / \mathrm{dL}$, glucose $93 \mathrm{mg} / \mathrm{dL}$, phosphate $5.1 \mathrm{mg} / \mathrm{dL}$, alanine aminotransferase $14 \mathrm{IU} / \mathrm{L}$ and aspartate aminotransferase $25 \mathrm{IU} / \mathrm{L}$. Blood gas analysis revealed $\mathrm{pH} 7.47, \mathrm{pCO}_{2}$ $26 \mathrm{mmHg}, \mathrm{pO}_{2} 47 \mathrm{mmHg}, \mathrm{HCO}_{3} 29 \mathrm{mmol} / \mathrm{L}$ and base excess $+1.2 \mathrm{mmol} / \mathrm{L}$. Corrected QT time was measured as $0.47 \mathrm{~s}$ from simultaneously taken ECG (N: $0.31-0.44 \mathrm{~s})$.

The patient was admitted to the pediatric intensive care unit, gastric lavage was performed and $1 \mathrm{~g} / \mathrm{kg}$ of activated charcoal through nasogastric tube was administered. The pa- 
tient was treated with the paper bag ventilation and at the end of the first hour, her numbness and contraction began to resolve. At the fourth hour, the heart rate and blood pressure were in normal levels. The blood gas analysis showed $\mathrm{pH}$ 7.4, $\mathrm{pCO}_{2} 38 \mathrm{mmHg}, \mathrm{pO}_{2} 52 \mathrm{mmHg}$ and $\mathrm{HCO}_{3} 23 \mathrm{mmol} / \mathrm{L}$. Corrected QT time was measured as $0.41 \mathrm{~s}$. The patient's symptoms, clinical findings, blood gas analysis and ECG findings returned to normal $4-6 \mathrm{~h}$ after the initiation of treatment. Carpopedal spasm rapidly responded to paper bag ventilation and normalization of arterial carbondioxide levels. The patient was discharged in the second day of hospitalization with normal systemic examination findings and resolved complaints.

\section{Discussion}

MPH is the primary treatment of ADHD and exerts its efficacy through neurotransmitters including dopamine, noradrenalin, adrenalin and serotonin. Also, it is thought to be exerting its efficacy on hyperactivity through dopaminergic activity in the certain areas of the brain [3]. A wide range of indications of the MPH make it the most commonly prescribed psychostimulant. Therefore, accidental or suicidal intoxications related with MPH have been increased dramatically. The present case was diagnosed as ADHD and had used MPH for 4 months.

After oral administration, MPH absorbed rapidly and almost completely from the gastrointestinal tract. Peak plasma concentration is reached in $2 \mathrm{~h}$. Clinical signs begin to appear 4 - $6 \mathrm{~h}$ after oral administration [4]. The clinical findings in our case have emerged $5-6 \mathrm{~h}$ after the ingestion of the drug.

Clinical findings related with high doses of MPH resemble the overdose of amphetamine-like drugs. In addition to neurologic (headache, depression, abnormal movements or rigidity, paranoia and hallucinations), cardiovascular (hypertension, tachycardia and chest pain) and gastrointestinal (vomiting and abdominal pain) changes, hyperthermia, dysrhythmias and convulsions can be detected in some cases [2]. However, there is no association between the severity of clinical symptoms and the dose of MPH intake [5]. Foley et al [6] reported that exposures to MPH in children were accidental and most of them were asymptomatic. However, exposures to MPH in adolescent were intentional and half of them were asymptomatic. In some reports $80 \mathrm{mg}$ [6] and 270 mg [1] MPH were found to be well tolerated. For this reason, determined toxic dose of MPH is unknown. In our patient ingestion of overdose of MPH at $110 \mathrm{mg}$ caused cardiovascular and neuromuscular findings as toxicity.

A reduction in cerebral blood flow in the setting of hyperventilation, hypocapnia and respiratory alkalosis may explain the neurologic symptoms associated with hyperventilation including paresthesias. Although there is no evidence that hyperventilation results in changes in total serum cal- cium levels, respiratory alkalosis may also trigger changes in ionized serum calcium levels with consequent binding of calcium to albumin, and it can result in paresthesias and tetany. Paresthesias and tetany in patients with hyperventilation are mainly secondary to decreased $\mathrm{PaCO}_{2}$ in the setting of respiratory alkalosis. Carpopedal spasm rapidly responded to paper bag ventilation and normalization of arterial carbondiokside levels [7].

Central nervous system stimulants can lead to hyperventilation. Blood $\mathrm{pCO}_{2}$ value decreases as a result of hyperventilation. These patients may present with very different clinical pictures including paresthesia and carpopedal spasm [8]. The cause of paresthesia and spasms due to hyperventilation is unknown; however, it may be related with the decrease in ionized calcium due to alkalosis [9].

In conclusion, $\mathrm{MPH}$ is commonly prescribed for patients with ADHD and has become easily avaliable drug for children. Side effects of MPH are well known and possible findings in the event of poisoning and drug abuse should be recognized. It should be known that the patients can apply with spasm carpopedal and it can be treated easily with the paper bag ventilation. Respiratory alkalosis may trigger changes in ionized serum calcium levels which should be taken into consideration rather than total calcium level.

\section{References}

1. Ozdemir E, Karaman MG, Yurteri N, Erdogan A. A case of suicide attempt with long-acting methylphenidate (Concerta). Atten Defic Hyperact Disord. 2010;2(3):103105.

2. Klein-Schwartz W. Abuse and toxicity of methylphenidate. Curr Opin Pediatr. 2002;14(2):219-223.

3. Challman TD, Lipsky JJ. Methylphenidate: its pharmacology and uses. Mayo Clin Proc. 2000;75(7):711-721.

4. Kimko HC, Cross JT, Abernethy DR. Pharmacokinetics and clinical effectiveness of methylphenidate. Clin Pharmacokinet. 1999;37(6):457-470.

5. White SR, Yadao CM. Characterization of methylphenidate exposures reported to a regional poison control center. Arch Pediatr Adolesc Med. 2000;154(12):11991203.

6. Foley R, Mrvos R, Krenzelok EP. A profile of methylphenidate exposures. J Toxicol Clin Toxicol. 2000;38(6):625-630.

7. van den Hout MA, Boek C, van der Molen GM, Jansen A, Griez E. Rebreathing to cope with hyperventilation: experimental tests of the paper bag method. J Behav Med. 1988;11(3):303-310.

8. Macefield G, Burke D. Paraesthesiae and tetany induced by voluntary hyperventilation. Increased excitability of human cutaneous and motor axons. Brain. 1991;114 ( Pt 1B):527-540. 
9. Steurer J, Pei P, Vetter W. [The effect of short-term hyperventilation on the concentration of ionized serum cal- cium]. Dtsch Med Wochenschr. 1997;122(28-29):887889. 